\title{
Pelatihan Pembuatan Animasi Sebagai Media Pembelajaran Bagi Tenaga Pendidik di MIN o3 Luwu
}

\author{
Nurfadhilah Arif ${ }^{1}$, Risal Mantofani Arpin ${ }^{2}$ \\ 1, 2, Akademi Teknologi Industri Dewantara Palopo \\ 1'nurfadilaharif@atidewantara.ac.id; ${ }^{2}$ risalmantofani@atidewantara.ac.id
}

\begin{abstract}
Abstrak
Penggunaan media digital dalam pebelajaran sangat berpengaruh terhadap keaktifan aktivitas peserta didik selama proses pembelajaran serta meningkatkan minat belajar tertama untuk kaarakter peserta didik di era digital seperti saat ini. Salah satu cara membuat media pembelajaran yang menarik yaitu dengan adanyanya animasi sesuai dengan tema pembelajaran. Oleh sebab itu, perlu diadakan pelatihan bagi para guru untuk meningkatkan kemampuan dalam penyajian materi pembelajaran. Tujuan dari kegiatan ini yaitu mengetahui dan menerapkan Langkah-langkah pembuatan animasi sebagai media pembelajaran dengan penerapan media digital. Objek utama dalam pelatihan ini yaitu para guru Madrasah Ibtidaiyah Negeri 03 Luwu. Kegiatan ini dihadiri oleh 17 orang peserta. Hasil kegiatan yang dilaksanakan yaitu meningkatkan pengetahuan pada guru dalam membuat animasi dalam presentasi materi pembelajaran bagi siswa dengan penyajian yang lebih menarik.
\end{abstract}

Kata Kunci: media pembelajaran digital, animasi, guru

\section{Pendahuluan}

Komponen penting dalam proses pembelajaran yaitu guru sebagai pendidik dan siswa sebagi peserta didik. Agar proses pembelajaran dapat berhasil, guru harus memiliki inisiatif, kreativitas, dan inovasi dalam merumuskan Langkah-langkah yang tepat dalam mendorong siswa untuk aktif belajar. Dengan demikian, siswa dapat menerima pengalaman belajar yang memadai kepada siswa. Pada saat proses pembelajaran berlangasung, terdapat suatu proses komunikasi antara guru dan siswa. Oleh karena itu dalam proses pembelajaran diperlukan suatu media pembelajran yang dapat menciptakan komunikasi yang baik antara guru dan siswa.

Dewasa ini, ilmu pengetahuan dan teknologi berkembang semakin pesat dan merambah ke dunia digital. Hal tersebut memberikan pengaruh terhadap berbagai bidang, salah satunya bidang Pendidikan. Prestasi belajar siswa di sekolah sering diindikasikan dengan permasalahan belajar siswa yang kurang efektif dalam memahami materi. Indikasi ini dipengaruhi oleh beberapa faktor diantaranya faktor proses pembelajran yang kurang efektof, bahkan siswa tidak merasa termotivasi di dalam mengikuti pembelajaran di kelas sehingga terkadang siswa sulit memahami materi yang sulit dicerna oleh otaknya.

Teknologi pembelajaran sebagai perangkat lunak digunakan dalam memecahkan masalah pembelajaran agar lebih menarik dan mudah dipahami bagi siswa, utamanya 
bagi karakter siswa di era digital seperti saat ini. Salah satu teknologi pembelajaran yang dapat digunakan yaitu aplikasi animasi sebagai media pembelajaran. Animasi merupakan objek yang bergerak sehingga terlihat hidup. Membuat animasi berarti menggerakkan gambar sepeti, kartun, tulisan, dan lain sebagainya. Dibandingkan gambar dua dimensi yang diam atau tidak bergerak, animasi jelas lebih disukai dan dapat membangkitkan antusiasme, emosi, dan semangat siswa. Selain itu, penjelasan mata pelajaran dalam bentuk animasi merupakan media yang praktis dalam menyalurkan ilmu kepada siswa.

\section{Metode Pelaksanaan}

Kegiatan ini dilaksanakan di Madrasah Ibtidaiyah Negeri (MIN) o3 Luwu selama 2 hari pada tanggal 5-6 Desember 2020. Subjek kegiatan pengabdian kepada masyarakat ini yaitu para guru MIIN 03 Luwu untuk peningkatan kemampuan guru dalam menyajikan materi pembelajaran. Metode yang digunakan berupa pelatihan. Pelatihan ini terdiri dua materi yaitu pembuatan animasi menggunakan Microsoft Power Point dan pembuatan presentasi yang menarik. Teknik pelaksanaan dimulai dengan pemaparan materi selama beberapa menit kemudian dilanjutkan dengan praktik pembuatan media pembelajaran oleh masing-masing peserta pelatihan dengan pendampingan dari tim pengabdian kepada masyarakat. Keberhasilan pelatihan ini dinilai dari output pelatihan berupa presentasi dari masing-masing peserta pelatihan. Peserta diharapkan mampu membuat presentasi pembelajaran yang menarik dan berisi animasi yang mudah dipahami.

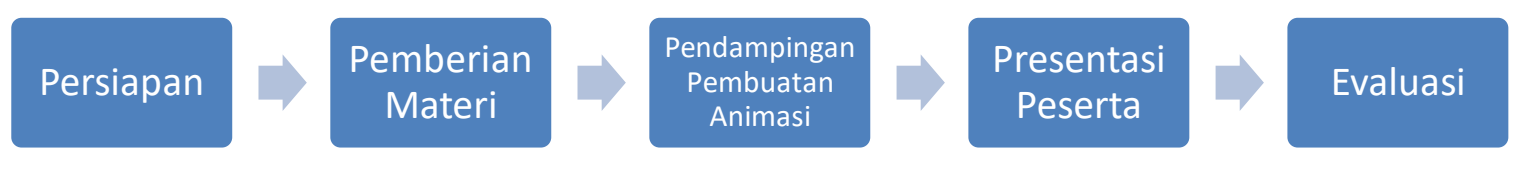

Gambar 1. Diagram alur Kegiatan Pengabdian kepada Masyarakat.

\section{Hasil dan Pembahasan}

Pelatihan pembuatan animasi sebagai media pembelajaran di MIN 03 Luwu secara garis besar terbagi ke dalam 5 tahapan. Pelatihan ini dimulai dari persiapan oleh tim pelaksana pengabdian kepada masyarakat berupa persiapan materi pelatihan, persiapan perangkat pelatihan, dan persiapan teknik acara pelatihan. Kemudian dilanjutkan dengan pemberian materi kepada para peserta dan mengadakan pendampingan pembuatan animasi bagi peserta. Selanjutnya, masing-masing peserta mempresentasikan hasil pembuatan animasi pembelajaran yang dievaluasi oleh tim pelaksana pengabdian kepada masyarakat.

Pada hari pertama, presentasi penyampaian materi pelatihan oleh tim pelaksana pengabdian kepada masyarakak. Presentasi terdiri dua materi yaitu pembuatan animasi menggunakan Microsoft Power Point dan pembuatan presentasi yang menarik. Presentasi tersebut dipaparkan secara bergantian oleh anggota tim pelaksana. Selanjutnya, setelah penyampaian materi, para guru mempraktekkan langkah-langkah membuat animasi pembelajaran menggunakan aplikasi Microsoft Power Point sesuai dengan mata pelajaran masing-masing yang diajarkan di kelas. Pembuatan animasi ini, didampingi oleh tim pelaksana pengabdian kepada masyarakat. Pada hari kedua, 
Vol. 2, No. 2, Mei 2021

ISSN 2721-4834

masing-masing peserta pelatihan, memaparkan hasil dari belajr membuat animasi pembelajaran. Kemudian, tim pelaksana pengabdian kepada masyarakat melakukan evaluasi.

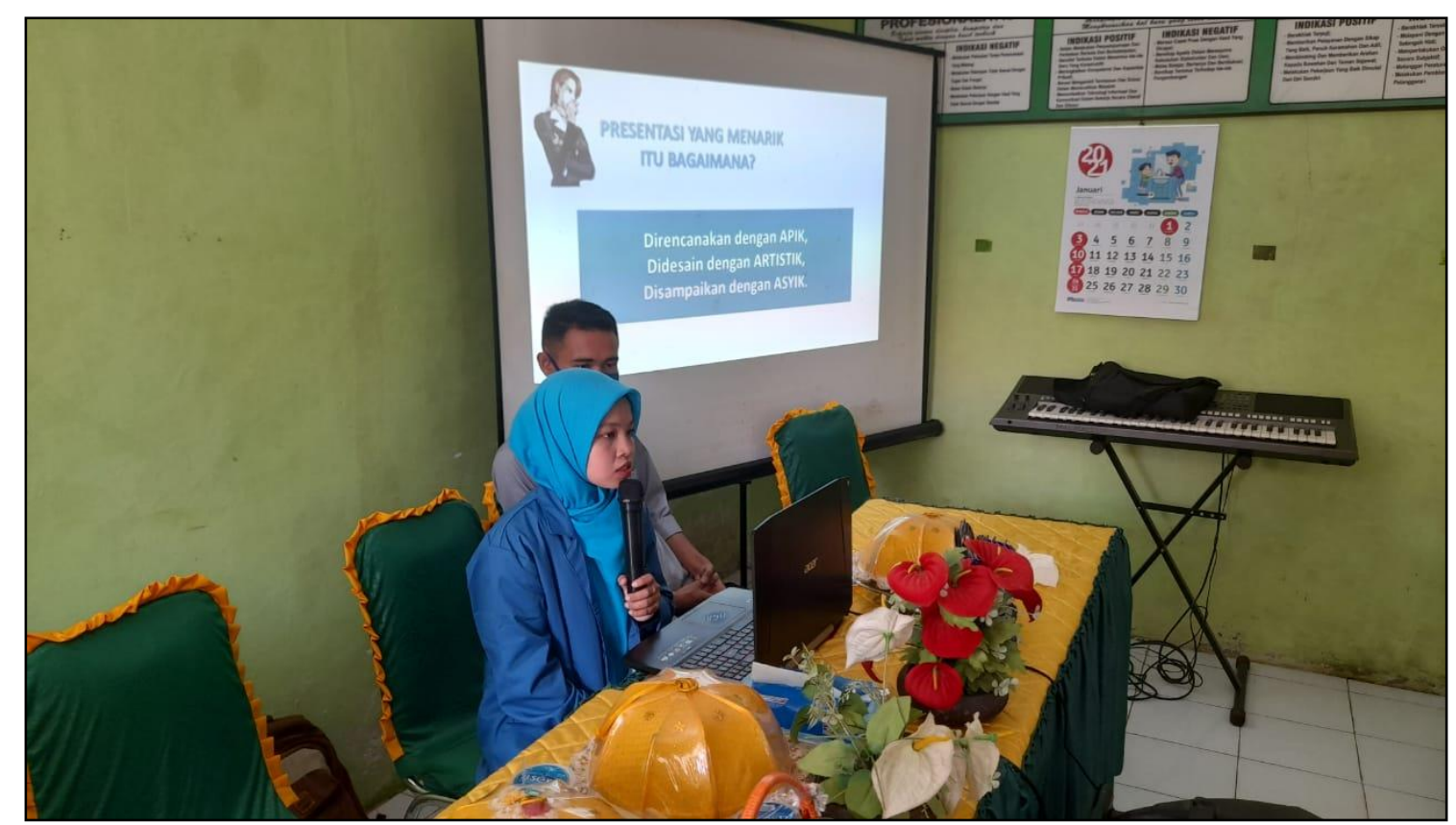

Gambar 2. Pemaparan materi oleh tim pelaksana pengabdian kepada masyarakat

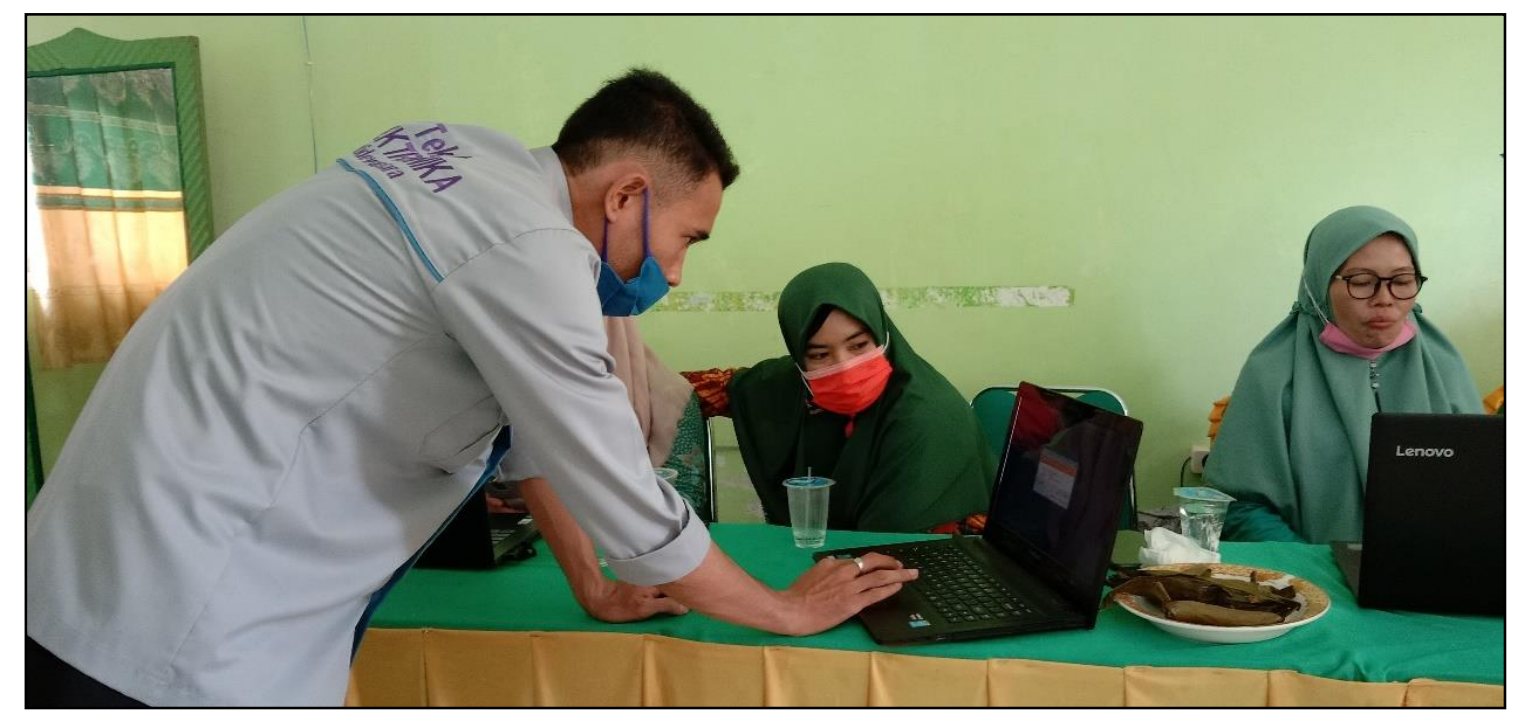

Gambar 3. Pendampingan pembuatan animasi pembelajaran 


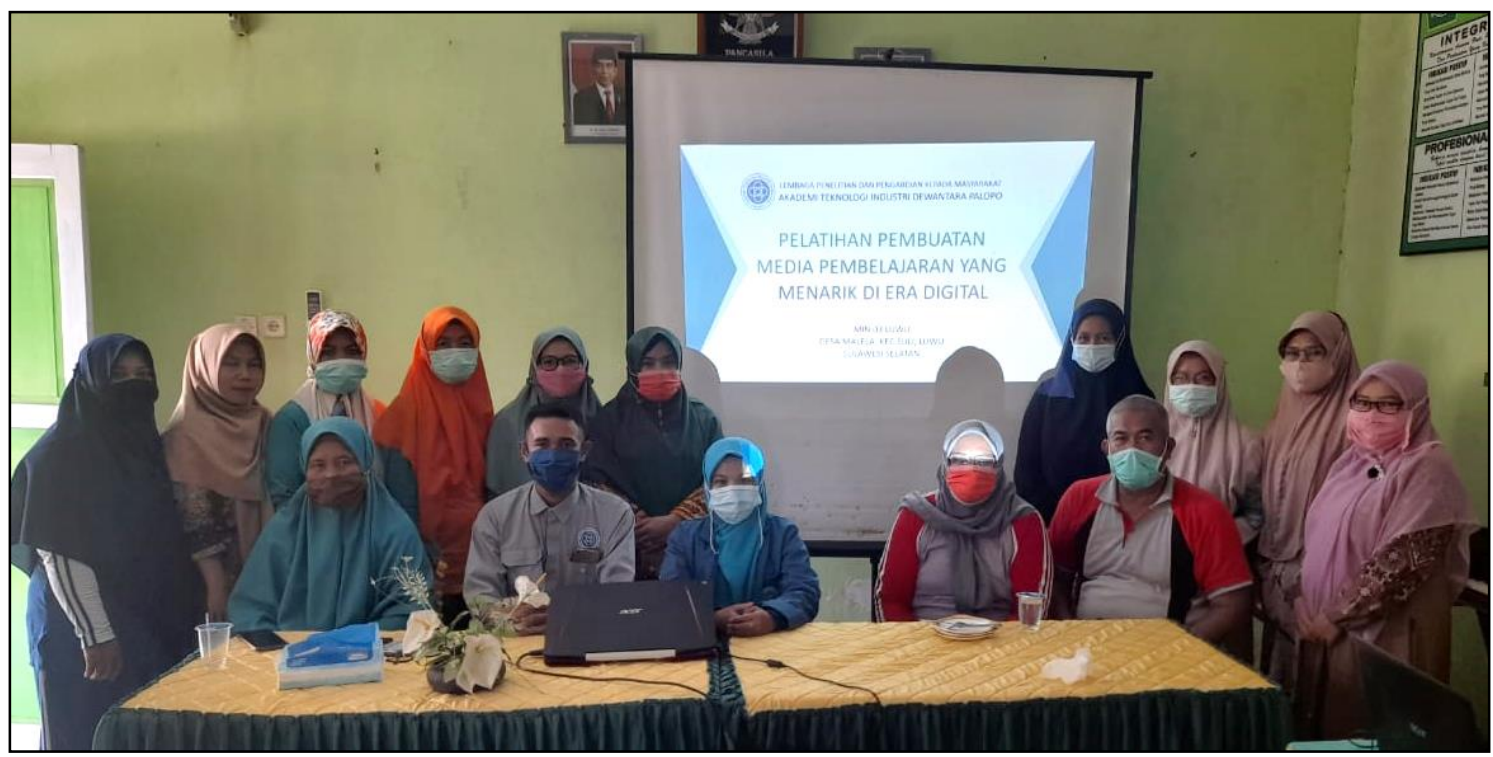

Gambar 4. Foto Bersama Peserta Pelatihan

Hasil yang diperoleh dari pelatihan ini yaitu meningkatkan kemampuan para guru dalam membuat animasi sebagai menia pembelajaran agar lebih menarik sehingga dapat membangkitkan semangat belajar siswa. Wadah yang digunakan dalam membuat animasi ini berupa tools presentasi sederhana yang umum digunakan. Sekitar $70 \%$ guru MIN 03 Luwu telah mampu memahami proses pembuatan animasi menggunakan Microsoft Power Point. Sedangkan, sekitar 30\% lainnya masih merasa awam dengan aplikasi Microsoft Power Point, sehingga tim pelaksana pengabdian kepada masyarakat masih memerlukan upaya lebih dalam pengenalan dan pengaplikasian setiap tools yang digunakan dalam pembuatan media pembelajaran yang menarik berupa animasi.

\section{Kesimpulan}

Kesimpulan dari kegiatan pengabdian kepada masyakat ini dengan tema "Pelatihan Pembuatan Animasi sebagai Media Pembelajaran bagi Tenaga Pendidik di MIN o3 Luwu" dinilai sukses. Hal tersebut dibuktikan dengan adanya peningkatan pengetahuan para guru dalam membuat media pembelajaran yang menarik menggunakan animasi. Hasil evaluasi yang diperoleh, sekitar $70 \%$ dari peserta pelatihan, dalam ha ini guru MIN 03 Luwu telah mampu memahami proses pembuatan animasi menggunakan Microsoft Power Point.

\section{Ucapan Terimakasih}

Ucapan terimkasih kepada Madrasah Ibtidaiyah Negeri o3 Luwu yang telah memberikan kesempatan kepada kami tim pelaksana pengabdian kepada masyarakat dari Akademi Teknologi Industri Dewantara Palopo untuk melaksanakan kegiatan ini. Terimakasih juga atas antusiasme para peserta sehingga kegiatan ini dapat terlaksana dengan baik. 
Vol. 2, No. 2, Mei 2021

ISSN 2721-4834

\section{Referensi}

Budiana, A., Muladi, M., \& Putranto, H. (2019). Pengembangan Media Pembelajaran Digital Sistem Antena Berbasis React Pada Mata Pelajaran Penerapan Sistem Radio dan Televisi Kelas XI Teknik Audio Video di SMK Negeri 2 Singosari. Jurnal Edukasi Elektro, 3(1). https://doi.org/10.21831/jee.v3i1.25895

Nengsi, S. (2015). Pengembangan Media Pembelajaran Animasi pada Materi Fotosintesis untuk Siswa Kelas VIII MTsN Koto Nan Gadang. BioCONCETTA, 1(2). https://doi.org/10.22202/bc.2015.v1i2.1504

Ponza, P. J. R., Jampel, I. N., \& Sudarma, I. K. (2018). Pengembangan Media Video Animasi pada Pembelajaran Siswa Kelas IV di Sekolah Dasar. Jurnal Edutech Universitas Pendidikan Ganesha, 6(1). https://ejournal.undiksha.ac.id/index.php/JEU/article/view/20257 